\title{
Wolfgang Bongers \\ Arqueología de una escritura pre/post/anti-dictatorial y estrategias intermediales de (anti)memoria en libros de Enrique Lihn
}

Pero la lengua, como ejecución de todo lenguaje, no es ni reaccionaria ni progresista, es simplemente fascista, ya que el fascismo no consiste en impedir decir, sino en obligar a decir.

Roland Barthes

Los regímenes totalitarios del siglo Xx han revelado la existencia de un peligro antes insospechado: la supresión de la memoria.

Tzvetan Todorov

\section{I}

El Arte de la Palabra (1980) de Enrique Lihn (1929-1988) puede leerse como una respuesta, una continuación con otros medios, o un comentario literario de la Lección inaugural (1977) de Roland Barthes y su programa de escritura presentado en el Collège de France, ${ }^{1}$ y a la vez es un texto profundamente latinoamericano y chileno. ${ }^{2}$ Uno de los temas de esta novela -algo atípica en la producción literaria de Lihn y de Chile en esa época, además de ser poco leída y comentada en la crítica chilena e internacional- es la aporía del trabajo intelectual frente al fascismo latente y las estructuras de poder en todo discurso político. Por lo tanto, Lihn es un autor que desde sus textos pone en jaque

1 Es llamativo que Barthes pronuncie su discurso - que ve una de las funciones significativas de la escritura literaria en el "trabajo de desplazamiento que ejerce sobre la lengua" (Barthes 2003: 123) apuntando a una apertura de todo discurso cerrado y unívoco -en un país de un gobierno democrático y en una institución intelectualmente muy prestigiosa, pero "fuera del poder" en la visión del mismo Barthes, mientras Lihn, aplicando estrategias análogas a las diseñadas por Barthes, vive en un país donde ejerce el poder un régimen militar.

2 Junto a Nicanor Parra, José Donoso, Jorge Edwards, Gonzalo Rojas -autores chilenos cuyos nombres tal vez circulen con más frecuencia en Europa- Enrique Lihn escribe y publica principalmente entre los años 60 y 80 en Chile, años marcados en este país por el ascenso del gobierno marxista-socialista de Salvador Allende en 1970, el golpe militar de 1973, y la dictadura pinochetista a partir de ese momento hasta 1989. 
y problematiza las diferenciaciones entre discursos llamados pre-, post- o antidictatoriales en la literatura, ${ }^{3}$ focalizando en su escritura más bien el double bind de estos discursos, su esquizofrenia en la imposición de sus denuncias y reclamos. Con todo, el discurso literario de Lihn podría clasificarse como escritura de resistencia a todo tipo de mecanismos totalitarios que operan en el lenguaje, independientemente del sistema político en que se inserten, no excluyendo, por supuesto, los sistemas democráticos. ${ }^{4}$

Por otro lado, Lihn es un escritor chileno que en los años sesenta lucha por un Chile socialista, pero que luego es muy crítico con la ortodoxia marxista que teme que se instale en el gobierno de Salvador Allende por la influencia que ejerce Fidel Castro desde Cuba, y después del golpe de 1973 vive en el exilio interior. Por esta razón, El Arte de la Palabra también es una novela (auto)reflexiva en el contexto chileno, una ficcionalización de las experiencias vividas por Lihn en esa época, reconocibles en muchos de los pasajes de la novela, y apoyadas por los paratextos críticos de Lihn que se publican en revistas, periódicos y libros de la época. En lo que sigue, quisiera proponer una lectura de esta novela y de El Paseo Ahumada (1983), un poemario abiertamente antidictatorial, estrechamente vinculado al contexto chileno en ese momento; una lectura que entiende la escritura de Lihn

3 En un contexto histórico, geográfico y epistemológico más amplio, podría decirse absurdamente que esta novela de Lihn es posdictatorial en Portugal y España (donde se publica), antidictatorial en Chile y Argentina (donde prácticamente nadie la lee en esa época, sino mucho después, en tiempos posdictatoriales), pero también en Cuba, si uno quiere aceptar las definiciones comunes del concepto de dictadura autoritaria, y a la vez respetar el contexto de la creación de la novela; y también puede considerarse predictatorial, tanto en un sentido manifiesto si pensamos en varios países africanos, como en un sentido latente en todas partes del mundo, porque el texto señala una amenaza permanente de la imposición de discursos y prácticas autoritarios o totalitarios en todo sistema político. Estas circunstancias muestran la fragilidad de la diferenciación temporal entre pre/anti/post-dictadura, que sin embargo, como veremos en el análisis de El paseo Ahumada, no carece de todo sentido.

4 Lo importante aquí es la latencia de las estructuras fascistas y totalitarias en el lenguaje y en todo discurso de poder, como señala Barthes; estructuras que se relacionan con y se manifiestan en estructuras políticas, como ocurrió en varios países del mundo durante el siglo XX, bajo gobiernos dictatoriales o regímenes militares. Por lo tanto, la diferencia que hace Hannah Arendt, entre el totalitarismo (nacionalsocialismo y estalinismo) y el autoritarismo (dictaduras), corresponde a un contexto distinto y se inserta en un análisis sociológico y politológico sobre el origen del totalitarismo y el terror como su esencia (cf. Arendt 2006). 
como la formación de un discurso crítico y autoreflexivo de memoria literaria, prefigurando la escritura "posdictatorial" en textos de autores chilenos tan diferentes como Diamela Eltit, Germán Marín, Alberto Fuguet o Pedro Lemebel. ${ }^{5}$

Lihn incorpora en varios de sus libros otros formatos y medios, dibujos, fotos, comics, happenings, registros cinematográficos, y realiza con esta estrategia un trabajo de memoria que no se reduce al medio discursivo de la escritura, sino que abre toda una dimensión intermedial de su ars memoria, ${ }^{6}$ comparable a las propuestas intermediales de Claude Simon o Michel Butor, W. G. Sebald, Peter Handke o Alexander Kluge, Jorge Semprún o Thomas Pynchon. ${ }^{7}$

En Los abusos de la memoria, cuya versión original en francés se publica en 1995, en pleno desarrollo de la era tildada de post-histórica, posmoderna, postcolonial y postdictatorial en el caso de varios países latinoamericanos, Todorov se dedica a criticar las prácticas contemporáneas de memoria. Señala que en un pasado en el que "las mentiras y las invenciones ocupan el lugar de la realidad [y] se prohíbe la búsqueda y difusión de la verdad" (Todorov 2000: 12) con la ayuda de un monstruoso aparato de control de la circulación de las informaciones, la lucha antiautoritaria en la política opositora, en el arte y en la literatura consiste en rescatar los retazos de las memorias individuales y colectivas amenazados por la extinción. Todorov, junto a otros críticos

5 En el contexto de la productividad de una "poética del fracaso", El Arte de la Palabra también puede considerarse precursora de las novelas de Roberto Bolaño, Los detectives salvajes (1998) y 2666 (2002) (cf. Sánchez/Spiller 2008). Para Idelber Avelar, que opera con el concepto de alegoría en Benjamin y de Man, memoria, duelo y alegoría se interrelacionan en varios autores latinoamericanos del postboom. En este sentido, la función de la ficción latinoamericana de postdictadura se encontraría en la tarea de realizar el duelo alegórico (cf. Avelar 1999).

6 Un hecho prácticamente ignorado por la crítica hasta la actualidad, y que además dificulta la clasificación de varias de sus publicaciones, que figuran bajo el título de "otras obras" en distintos lugares, p.ej. en el muy útil portal electrónico $<$ memoriachilena.cl>, donde se encuentran reediciones de libros de poesía y prosa de los años 70 y 80 , de poca circulación o difícil de conseguir, de autores como Nicanor Parra, Juan Luis Martínez, Raúl Zurita, Enrique Lihn.

7 En el contexto chileno, La nueva novela (1977/1985) de Juan Luis Martínez es un extraordinario ejemplo de una estética intermedial cuyo eje son los efectos de la (des)aparición y el desplazamiento de objetos, palabras y personas (entre ellos $\mathrm{Na}$ poleón, Hitler, Tardieu, Pound, Magritte, Deleuze, Morgenstern) a través de una escritura intertextual inabordable. Las operaciones poéticas de Martínez llevaron a Lihn a comentar la obra en varias ocasiones (cf. Lihn 1997a: 177-180, 197-201). 
de la cultura posmoderna, opina que en tiempos de las democracias liberales, consumistas y posmodernas, el proceso se ha invertido para llegar, no obstante, al mismo resultado. Asistimos, dice, a una sobreabundancia de información que también aniquila la memoria, hecho que acercaría las sociedades posmodernas a las que vivieron o viven bajo un régimen autoritario respecto de su modus memorandi. En sintonía con el epígrafe de Le Goff que abre el libro y enfrentándose al culto a la memoria y al "delirio conmemorativo" (Todorov 2000: 50) de un pasado común, uniforme y homogéneo de las clases medias en las sociedades (pos)modernas, Todorov sostiene que el mecanismo de la memoria entre la supresión o represión y la conservación o recuperación de experiencias y datos del pasado debe responder a la utilización del pasado para el presente, y de la memoria al servicio de la justicia en lecturas ejemplares del pasado como modelo liberador de memoria que se convierte en "principio de acción para el presente" (Todorov 2000: 31); una fórmula optimista, a pesar de todo, que Enrique Lihn no compartiría tan rotundamente.

Andreas Huyssen, otro analista de la cultura y la memoria posmoderna, hace un análisis de la "búsqueda del futuro perdido" que acompaña el cambio del milenio, y señala también la obsesión acerca de la memoria en la actualidad, el "marketing masivo de la nostalgia" y del pasado que vende mejor que el futuro en todos los medios masivos, y el afán historicista de una "musealización del mundo". Huyssen explica estos fenómenos con el "impulso subliminal del deseo de anclarnos en un mundo caracterizado por la creciente inestabilidad del tiempo y por la fracturación del espacio en el que vivimos" (Huyssen 2002: 24). Huyssen destaca los recuerdos terroríficos de las grandes guerras y los regímenes totalitarios y militares que nos deparó el siglo XX, y habla de la "globalización del discurso del Holocausto" como "tropos universal del trauma histórico" (Huyssen 2002: 16-17), de genocidios y catástrofes causadas por la violación de los derechos humanos durante la segunda mitad del siglo XX en cualquier parte del mundo. Por el otro lado apunta a la "necesidad fundamental de las sociedades [pos]modernas de vivir en formas extensas de temporalidad para asegurarse un espacio desde el cual hablar y actuar" (Huyssen 2002: 34). Siguiendo la línea benjaminiana del análisis de los medios masivos del siglo XX, y en oposición al puro rechazo de la industria cultural que realizaría Adorno, Huyssen reivindica dialécticamente una memoria 
global, pero vivida, activa, transitoria, humana y social en las prácticas locales y nacionales para garantizar un futuro $-\mathrm{y}$ no un pasado- con memoria, en réplica a los mitos del cibercapitalismo y de la globalización que tienden a negar las relaciones espaciotemporales y a eliminar un trabajo de memoria cultural.

Andreas Huyssen y Tzvetan Todorov coinciden en señalar que el fenómeno de la memoria, en el mundo globalizado y desde los años sesenta del siglo pasado en adelante, ha venido a ser cada vez más comercializado y espectacularizado, y que es cada vez más pertinente la distinción entre "pasados utilizables y datos descartables" (Huyssen 2002: 23, cf. acerca de Chile también Brunner 2002). En este contexto, las diferentes estrategias en la escritura de Lihn son doblemente interesantes, porque desconciertan con su doble sentido, sus juegos y sus aberraciones intermediales, en el contexto de la dictadura represiva en Chile, donde rige un enunciado único del orden establecido, un relato unificador y prescrito de la obediencia, de la subordinación, de la memoria y del olvido (Cánovas 1986a; Brunner 1983; Richard 2004). De allí surgen las siguientes preguntas: ¿Cómo contrarrestar y desescribir los mecanismos discursivos y políticos de la represión y de las estructuras totalitarias desde la literatura? ¿Cuáles son, en el contexto del poder ejercido por un régimen militar, las estrategias literarias para generar formas heterogéneas e intermediales de memoria? “¿Cómo verbalizar un discurso que está prohibido?” (Lihn 1997d: $495)^{8}$

Lihn estudia arte en la Universidad de Chile, escribe poesía y pro-

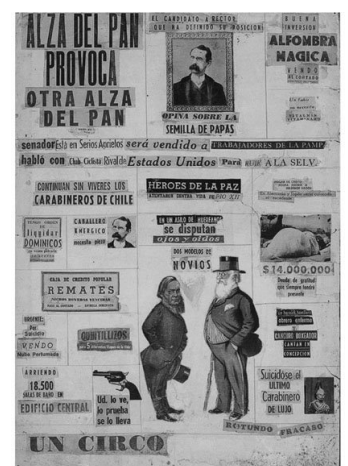
sa, dibuja comics, monta obras de teatro, realiza performances y videos. Entre 1949 y 1988, Lihn publica numerosos libros de poesía, dos colecciones de cuentos, tres novelas y álbumes multimediales, además de sus ensayos y artículos de crítica literaria en revistas nacionales e internacionales. Llama la atención el hecho de que de las tres novelas, ninguna se haya publicado en Chile, sino las dos primeras, Batman en Chile (1973) y

8 Lihn sobre el libro de Rodrigo Cánovas (1986b): Lihn, Zurita, Ictus, Radrigán: literatura chilena y experiencia autoritaria. 
Orquesta de cristal (1976) en Buenos Aires, la última poco antes de que tuviera lugar el golpe militar, y la tercera, El Arte de la Palabra (1980), en Barcelona. Durante los años 50 y junto a Nicanor Parra y Alejandro Jodorowsky, Lihn es parte de la generación de renovación intelectual que se opone radicalmente al criollismo y lirismo reinantes en el Chile de esa época. Con ellos y otros artistas, Lihn, en 1952, diseña e instala en la zona peatonal de Santiago Quebrantahuesos, un diario mural tipo collage. Es una BROMA surrealista con fuerte carga crítica a los medios de comunicación y las estructuras de poder de la época, una obra que tuvo una gran repercusión en el mundo artísticocultural. Pero después, su producción más impactante es la poesía. $L a$ pieza oscura (1963), Poesía de paso (1966) y La musiquilla de las pobres esferas (1969) lo ubican pronto entre los más destacados poetas modernos de habla española, vinculados en la crítica a una escritura excéntrica, existencialista y a una estética neobarroca (Severo Sarduy; cf. Foxley 1995). Lihn hace su primer viaje a París en 1965, gana el premio Casa de las Américas en 1966 por Poesía de paso y pasa un año en La Habana entre 1967 y 68, en pleno auge del boom, y cuando tienen lugar en Cuba varios encuentros de escritores latinoamericanos, especialmente el gran Congreso Cultural en 1967. De vuelta en Chile, Lihn edita la revista literaria-cultural Cormorán $(1969 ; 1970)$ y dirige un taller de poesía en la Universidad Católica de Chile.

\section{II}

Junto a un gran número de intelectuales latinoamericanos, Lihn participa durante los años 60 y 70 desde sus textos publicados en varios diarios y revistas en la formación de discursos políticos y estéticos que giran alrededor del compromiso intelectual y sus implicaciones políticas, a saber, la polémica sobre Cuba y especialmente el caso Padilla. Lihn destaca el gran valor cultural que significa la institución de la Casa de las Américas en todos esos años, pero, desilusionado, critica las estructuras autoritarias que se están consolidando en la política de Fidel Castro, con miras preocupadas a lo que sucede en Chile en ese momento clave para la construcción de un nuevo gobierno socialista. Lihn se perfila primero como militante intelectual en el trabajo de la Unidad Popular, pero defiende ante la política procubana de Allende el "carácter pluralista de la sociedad chilena, diseñando el amplio con- 
torno a que debe extenderse la creación de una nueva cultura" (Lihn 1997e: 465). Es interesante para el análisis de El Arte de la Palabra cómo Lihn observa retrospectivamente, en un texto sobre el caso Padi1la, los sucesos durante el Congreso de La Habana, en el que

proliferaban artistas e intelectuales transportados, en cantidades apreciables e indiscriminadamente, desde el Boulevard Montparnasse o la isla de San Luis, al hotel Habana Libre. Y fue conmovedor ver cómo estos invitados de inequívoco aspecto burguesoide y liberaloide, alzaban los puños al cierre del Congreso, con un gesto de Patria o Muerte, después de estampar su firma al pie de un documento ultrarrevolucionario (Lihn 1997b: 432).

Esta descripción irónica de una escena del Congreso Cultural de Cuba, y experiencias similares en otros encuentros organizados en Chile durante 1969, son probablemente los disparadores del núcleo narrativo de la novela, en la cual se celebra un curioso Congreso de Escritores en la ficticia República Independiente de Miranda. Junto a los posicionamientos de los intelectuales frente al caso Padilla, en pro o en contra de la revolución cubana, los efectos del boom de la literatura latinoamericana de los años 60 en el mercado mundial y, simultáneamente, la recepción de las nuevas teorías literarias que desde Francia empiezan a circular por el mundo y que compiten con los conceptos del realismo mágico y lo real maravilloso, de origen latinoamericano, generan un contexto discursivo complejo: la noción del intelectual comprometido y una literatura comprometida en todas sus variantes, se entremezclan y se superponen con las ideas sobre "la muerte del autor" y la productividad del texto y la lectura como praxis cultural en teorías de cuño estructuralista y postestructuralista. Desde 1972 y hasta su muerte en 1988, Lihn es profesor e investigador de literatura en el Centro de Estudios Humanísticos de la Facultad de Ciencias Físicas y Matemáticas de la Universidad de Chile, uno de los pocos lugares de trabajo académico-crítico en una casa de estudios intervenida por el gobierno militar desde 1973. Es allí donde se dedica, entre otras cosas, a la lectura y a la enseñanza de textos de Foucault, Barthes, Lacan, Derrida. Las teorías del texto, el análisis discursivo y la semiología como nuevos paradigmas de conocimiento son para Lihn una suerte de camino de rescate intelectual, después de haber sido testigo inmediato de los fracasos latinoamericanos de revoluciones políticas y estéticas de la izquierda que terminaron por diferentes 
caminos en regímenes autoritarios. Durante los años 70, no obstante, Lihn realizó varios viajes a Europa y EE.UU. como profesor invitado, con becas concedidas por el gobierno de Francia en 1975 y de la Fundación Guggenheim en 1978.

\section{El Arte de la Palabra}

Tanto el título como la tapa del libro remiten a la teatralidad como matriz de la escritura del libro. La tapa muestra dos figuras sobre un escenario teatral: en el primer plano un personaje farsesco, caricaturesco, circense, que se pone a anunciar la próxima escena con una hoja en la mano y cuya cara se parece bastante a la de Enrique Lihn, del cual vemos también una foto en la contratapa del libro. En el segundo plano de la tapa hay un niño que levanta el telón para mirar lo que sucede afuera. Como señala Rodrigo Cánovas en su ensayo sobre esta novela (1986b), se trata de una ilustración hecha por Aubrey Beardsley (1872-1898), un dibujante, ilustrador, caricaturista y poeta inglés del fin del siglo XIX, conocido por las ilustraciones en Salomé de Oscar Wilde y sus trabajos en las revistas del esteticismo y decadentismo británico The Yellow Book (1894-1897) y The Savoy (1896). Beardsley es de alguna manera un alter ego, una máscara tanto del mismo au-
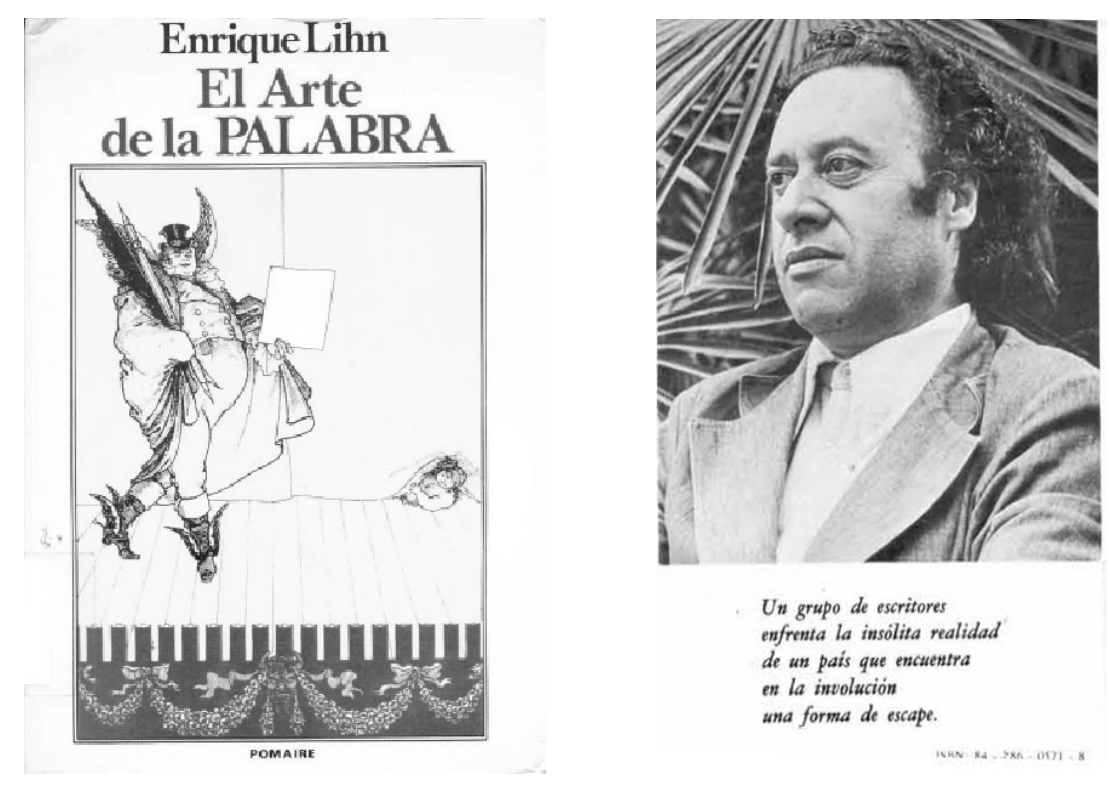
tor Lihn, que dibuja y escribe caricaturas y edita revistas de literatura y estética, como de Gerardo de Pompier, el personaje central de la novela, hijo del decadentismo pomposo europeo que brilla en los discursos, diarios y cartas insertados en el libro. Pompier aparece en forma constante en la revista Cormorán (1969-1970) y en otros textos que publica Lihn. En la novela anterior, La orquesta de cristal, es uno de los músicos que tocan instrumentos hechos de cristal, y que nunca llegan a realizar su concierto. Como "autor desconocido" de cartas y como autor falso de un libro titulado "El arte de nadar en el mar y en los ríos, aprendido sin maestro", atribuido a otro autor inventado a manera borgeana, llamado A. P. Duflot, está presente en muchos de los ensayos de Lihn. En el "book action" Lihn \& Pompier, de 1978, un álbum mutimedial que se basa en un happening realizado el 28 de diciembre de 1977 (día de los Santos Inocentes) y que Lihn concibe en trabajo conjunto con el reconocido artista visual Eugenio Dittborn mientras escribe El Arte de la Palabra, Pompier es visualmente el doble de Lihn, o al contrario: en esta documentación del happening, que se convierte en una curiosa obra de arte con un nuevo estilo y un nuevo lenguaje, el autor pasa a ser su creación, los dos manifiestan y muestran su ser "yosotros", tanto en el texto como en las fotografías del libro. El happening y el álbum, producto genuinamente intermedial donde se cruzan y dialogan varios medios y formas de expresión como pintura, poesía, fotografía, cine, actuación y performance, es un importante intertexto de El Arte de la Palabra, ya que aquí tiene lugar in actu la transformación entre varios sujetos del lenguaje que operan en el discurso de Lihn. Dice el autor en las conversaciones con Pedro Lastra: "Tendría que ver con una cierta descomposición sufrida por el sujeto poético, el cual, incapaz de mantener su unicidad, a través de un proceso de pluralización, se reconoce finalmente como máscara." La máscara, como "personaje que arranca del lenguaje mismo" (Lastra 1990: 125) y pronuncia discursos aberrantes, es la modalidad narrativa central de la novelística de Lihn. ${ }^{9}$

Por todo lo dicho, la caricatura de la tapa de la novela abre un juego de heteronimias y desplazamientos de sentido que prefigura lo que les espera a los lectores en el interior del libro: "el arte de la palabra"

9 Sobre el álbum y su relevancia para la compleja estética de Lihn cfr. Lange (2006a). 
es un arte de la palabra invertida y pervertida por discursos burlescos, serio-cómicos, satírico-teatrales. ${ }^{10}$ La novela se compone de retazos textuales: una serie de cartas enviadas entre los personajes que escriben y raramente hablan entre ellos; fragmentos del diario de Gerardo de Pompier; poemas insertados y forzosamente malos; recortes de prensa ficticios; discursos políticos y conmemorativos; entrevistas inventadas; un prólogo-epílogo provisorio; varios capítulos donde habla un narrador-testigo-participante del Congreso de Escritores; y finalmente un extenso, ya por su título absurdo suplemento del colofón que cierra la novela, y en el que habla el "autor" sobre el libro y el contexto de su creación. Estamos, pues, ante una novela sumamente autoreflexiva (o autotextual en la terminología de Genette) y anti-alegórica, ${ }^{11}$ que pone en escena su propio acto de escritura en varios niveles. También es un texto en el que se nota permanentemente la presencia de intertextos europeos y americanos, tanto a nivel literarioartístico $^{12}$ como a nivel teórico-crítico, especialmente en las referencias explícitas y alusiones implícitas al estructuralismo francés: están presentes literalmente Claude Lévi-Strauss, Roland Barthes, Jacques Derrida, Jacques Lacan, y se habla de la teoría del Nouveau Roman y del grupo Tel Quel. A la novela le acompañan, junto al álbum Lihn \& Pompier, varios paratextos del autor, en los que explica sus métodos y define sus posturas tanto estéticas como políticas, reunidos junto a muchos ensayos y artículos publicados entre 1950 y 1990 por el compañero de ruta, Germán Marín, en el extenso volumen El circo en

10 En una de las entrevistas con Lastra sobre sus novelas, Lihn las ubica en la tradición picaresca (véase Lastra 1990: 114, 120).

11 Lo que significa también un cuestionamiento de lecturas de "duelos alegóricos" en el sentido de Avelar, cuya aplicación se complicaría en el caso de Lihn. Tal vez correspondería más a una "mnemotécnica artificial" que construye la literatura como un "modelo de paradigma para la comprensión cultural" (cf. la introducción en Haverkamp/Lachmann 1991), llevado, eso sí, a su extremo en forma de antimemoria.

12 Cf. acerca de la densa red intertextual y la (in)utilidad de desentrañarla: Francisca Lange (2007): "Sobre El arte de la palabra y la paranoia de una modernidad tardía", inédito. Como señala Lange, varios personajes-escritores invitados al congreso de Miranda, a través de sus nombres alusivos, hábitos exagerados o discursos pronunciados, han sido "identificados" en la crítica como personas reales, pertenecientes al ambiente intelectual chileno y latinoamericano de los años 70 . Pero queda claro que aquí se despliega el mismo juego ambiguo de identidades que Lihn aplica a sí mismo, y en el que esa "realidad" forma parte de la máquina discursiva de la cháchara. 
llamas (Lihn 1997a). El Arte de la Palabra es, finalmente y más allá del libro publicado bajo este título, un amplio proyecto de escritura y de memoria.

Con todo, sería interesante considerar esta novela y sus configuraciones discursivas de los años 70 -dentro de los esquemas del postboom - como una nueva Rayuela (Julio Cortázar 1963), liberada de la carga existencialista y del "romanticismo negativo", que observa el mismo Lihn acerca de la obra de Cortázar en la "base o en la estructura novelística de Rayuela, que es la novela que mejor expresa el desarraigo del latinoamericano, la novela del destierro dentro y fuera de Latinoamérica" (Lihn 1997a: 620). El Arte de la Palabra necesariamente plantea otras dudas sobre una posible novela latinoamericana y una posible memoria cultural después de los fracasos políticos y estéticos en la región, pero son llamativas las similitudes en la búsqueda de una nueva forma de escritura y un nuevo lenguaje: Cortázar escribe con y contra todo el bagaje metafísico y estético de Occidente (y por partes de Oriente), en un clima parisino marcado por las experiencias existencialistas, patafísicas y surrealistas de un latinoamericano "afrancesado", las discusiones entre los amigos del Club de la Serpiente sobre el destino del mundo después de la Segunda Guerra Mundial y ante las nuevas guerras y amenazas de destrucción mundial durante la Guerra Fría; Lihn se ubica con la inscripción en una escritura deconstructivista, travestista, autoparódica, más allá de un proyecto "moderno" de literatura, sea cual fuere su estructura. Los dos comparten su predilección por un alter ego literario-crítico que aparece en la novela y en paratextos explicativos, en el caso de Cortázar es Morelli, personaje y teórico de la novela "prescindible" que quiere construir un discurso literario absolutamente nuevo; y en el caso de Lihn es Pompier, el anti-Morelli, un personaje farsante-excéntrico-carnavalesco, que no es capaz de ser otra cosa que el vociferador y el ejecutor cínico de la cháchara. ${ }^{13}$

13 En cierto sentido, existen también vasos comunicantes entre la propuesta de una nueva escritura en El Arte de la Palabra y la desarrollada por Ricardo Piglia en Respiración artificial (1980), sobre todo respecto de su actitud frente al lenguaje ficcional mezclado con un lenguaje crítico, y de la fiabilidad o autenticidad de lo narrado, con guiños a las estrategias borgeanas. Además, Hitler es personaje en los dos textos y el nombre funciona claramente como un indicio de una estructura política que las dos novelas denuncian a través de estrategias como la parodia, el 
Desde el primer capítulo titulado "A manera de sinopsis. Borrador de un prólogo o de un epílogo provisorio", el libro se presenta como una colección de fragmentos con una estructura inconclusa. El narrador es participante de un Congreso de Cultura convocado por el Protector-dictador vitalicio de la República Independiente de Miranda -nombre escogido en homenaje al misterioso país latinoamericano cuyo embajador corrupto es vendedor de drogas en El discreto encanto de la burguesía (1972) de Buñuel-y hace de la misma "inconclusión profunda" del libro, de su carácter provisorio e incoherente, su tema. Enumera, además, los "lugares no escritos de la novela" ( $A P: 9)$, de los cuales surgió el presente borrador de este prólogo-epílogo. A pesar de la extrema autoparodia deconstructiva (o parodia autodeconstructiva) que se refleja en los pasajes de este capítulo, los lectores reciben varios datos importantes para entender la "trama" de la novela. Se conoce a don Gerardo de Pompier, en su calidad de presidente del Congreso de Escritores que tiene lugar en Miranda, en el Hotelcastillo Cosmos, antigua residencia de Encanta-Flor, "poeta puro y olvidado" de Miranda, quien

oculta en él, como si lo hiciera en el interior de sí mismo, los originales de El Arte de la Palabra, adelantándose a los agentes que han sido comisionados para destruirlos. Poco antes de su muerte -dice el siguiente párrafo- esos papeles rescatados del fuego de los Servicios de Seguridad, como si hubieran viajado por condensación convertidos en una nubecilla, llueven sobre la mesa del editor, o algo así ( $A P: 10)$.

Parece que se trata de la historia del libro de Encanta-Flor, un escritor disidente y crítico de su país, que precisamente NO se propone a relatar la novela; se convierte más bien en libro-proyecto, un texto inconcluso, fragmentario, burlesco y satírico, la única forma posible de escritura según Lihn. Poco después, se realiza una burla del tablero de dirección de Rayuela que adquiere más fuerza en todo el contexto antes desarrollado:

Los lectores (ahora y en este caso no se trata de bromas) pueden iniciar la lectura de El Arte de la Palabra por cualesquiera de sus capítulos o fragmentos de cualquier tipo superiores a la frase; entrar en la materia de este discurso por las miliuna puertas de entrada y/o de salida, pues es nada o casi nada lo que se les puede proponer como regla o lógica de continuidad $(A P: 11)$.

pastiche, la deformación textual y una intertextualidad extrema que lleva a una reescritura historiográfica. 
Esta escritura discontinua y autodestructiva toma la palabra para desescribir sus sentidos y desplazarla a otro lugar que nunca sería el propio sentido de la palabra enunciada.

Hacia el final del primer capítulo se menciona otra historia de otro personaje, Roberto Albornoz, espeleólogo, paleontólogo y gran amigo de Pompier, que tampoco se contará in extenso, según el prologuista. Ese amigo bajará a una cueva para encontrar al Saurio Nuevo, pero

[d] esde el punto de vista del proyecto (de la novela), probablemente no serán saurios los que encuentre Albornoz, ni mucho menos saurios mutantes y progresivos, sino hombres regresivos, obligados por ciertas circunstancias a esconderse en las intimidades geológicas de Miranda, ese terrón paleozoico $(A P: 12)$.

Es más que obvia la analogía respecto de la situación del exilio interior o del encarcelamiento que sufren los escritores chilenos durante la dictadura y la censura, subrayado por la introducción en este contexto del personaje del Protector-dictador de Miranda, que consiente con el refugio en la cueva para evitar las "prisiones políticas" ( $A P: 13)$ existentes en su país. En los últimos párrafos del prólogo-epílogo, y en la voz del prologuista, el texto, una vez más, se cierne sobre si mismo diciendo que se trata de una novela que

peca de negligencia total en relación a los acontecimientos narrados, ninguno de los cuales parece haber sido conducido hasta alguna de sus posibles consecuencias. Considero, sin embargo, este descuido aparente como un signo que, si no nos introduce en la inconclusión profunda del texto, la traiciona superficialmente. [...] La parálisis del relato proviene de esas aludidas profundidades, que son también el hontanar de su incontinencia latente $(A P: 13)$.

La traición se transforma en método del discurso, en estrategia de sobrevivencia. Todo el texto de esta novela es esto: una traición de la palabra en la palabra vacía (Lacan), que en otro sentido es precisamente el arte de la palabra en tiempos de prohibición de la palabra disidente: "El yo escribiente de esta novela, en una perfecta homología con el mundo que describe, oscila entre el ser y el no ser, se tambalea como un borracho perdido" ( $A P$ : 13). La escritura, entonces, se presenta como la resistencia al sentido de la palabra corrompida de la represión, abriendo un espacio textual de la antimemoria. Don Gerardo de Pompier es y aplica la palabra traidora 
do de Pompier es y aplica la palabra traidora y traicionada, y ya desde su nombre es un "meteco" monstruoso. ${ }^{14}$

En otros textos, Lihn ofrece variantes de explicaciones sobre lo que significa Pompier para su producción literaria. ${ }^{15}$ Aquí va una de ellas:

El nombre y el título de don que se le antepone, dan cuenta de una generalidad decimonónica (Gerardo es nombre que abunda en el folletín) y de una prosopopeya vacía. Don es título -sostiene el diccionario- "que ya no se niega a ninguna persona bien portada". El personaje, en lugar de apellido, ostenta una panoplia de significados que aluden a sus atributos. Como adjetivo, Pompier es palabra francesa, sinónimo de lo banal y enfático, aplicado hasta el día de hoy a toda suerte de estilos retrógados (políticos, filosóficos y artísticos). El lenguaje que don Gerardo y aquél que lo habla y en que es escrito (también cuando habla, ciertamente) es la exposición y, de alguna manera, el análisis, la deconstrucción [...] de lo que voy a llamar aquí la palabra establecida, respecto de la cual quiero o pretendo hacer una suerte de teratología: estudio, en acto, de ciertas anomalías o monstruosidades del lenguaje. La cháchara -la palabra vacía de Lacan- combinada, como ocurre corrientemente, con 'la afectación de gravedad y pompa' y con tales o cuales propiedades del llamado discurso obsesivo. Palabra desplegada bajo la falsificación del signo del 'Poder de las palabras' o de las palabras del poder; estas son algunas modalidades (teratológicas) del lenguaje-Pompier (Lihn 1997a: 573-574).

La cita es solo una pequeña parte de los niveles de significación que puede adquirir la palabra "Pompier" y que el texto citado despliega en varias páginas. Lihn presenta en este y otros paratextos una metodología de análisis del personaje Pompier, y en el mismo artículo comenta varios textos críticos dedicados a la novela poco después de su publicación. Pompier, un don nadie, es, entonces, a la vez símbolo y antisímbolo de la cultura europea-francesa del fin del siglo y de la Belle Époque, tan determinante para la formación del discurso de la inteligentsia burguesa en Chile y desacreditada después de los fracasos en las experiencias

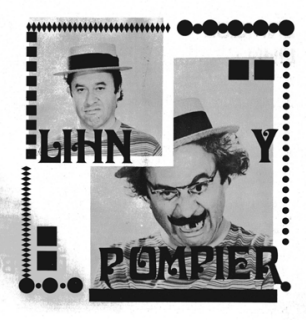

14 El metequismo es un "galicismo mental" que Lihn define en diversos textos y de distintas maneras; aquí una versión que contiene un núcleo que se repite en casi todas las definiciones: "ilusión del provinciano de integrarse en el mejor de los mundos compensatorios, que parece liberarlo de la opresión del provincianismo cultural" (Lastra 1990: 117).

15 Cf. los textos reunidos en el capítulo "Gerardo de Pompier" (Lihn 1997c). 
políticas del país; es a la vez metonimia y metáfora de una "forma de ser" chilena, entre una autenticidad inventada y una identidad cultural perversa entre Europa y Latinoamérica; es heterónimo del autor Lihn con todo el bagaje esquizofrénico que lleva el nombre y a la vez operación deconstructiva en el lenguaje pervertido.

Mientras la cháchara pomposa se pone en escena desenmascarándose y traicionándose en el mismo acto discursivo de Pompier, en el "Discurso nacional del Protector" ( $A P:$ 237-257) se celebra irónicamente, y con aplausos intercalados de una masa informe y callada, la palabra establecida, corrompida, mentirosa del dictador que se revela vacía de manera mucho más cruel, porque se cree poderosa. Un ejemplo: "Una mano de hierro protege en este país la democracia de los mejores, en nombre del bien común, y todo lo demás es silencio" ( $A P$ : 243). Este dictador es la antifigura máxima en la novela, y su discurso es el de Mussolini, Hitler, Franco, Pinochet, Videla, Castro, y tal vez con más trascendencia aún el discurso desfigurado del gran dictador chapliniano en la película homónima de $1940 .{ }^{16}$ En la novela hay un escritor invitado al Congreso con el nombre de Otto Federico Hitler, un personaje con bajo perfil hasta el último capítulo, "Metamorfosis de Otto Federico Hitler", donde el narrador habla del suicidio del "andrógino imperfecto" que "ha coagulado el proceso de su androginización divina en la fase de su transformación en mujer" (AP: 316). Se describe exhaustivamente el destino y la apariencia post mortem de Hitler, un travestí comparable al propio texto que lo describe. Poco antes de la expulsión definitiva de los participantes del Congreso por ser éste un acto subversivo y opositor, otro personaje, el escritor Juan Meka, desaparece del hotel Cosmos, es metido preso y asesinado por el régimen militar. Como nos cuenta el narrador, el Congreso se desarrolla en el Cosmos, antigua residencia del poeta disidente EncantaFlor, "caserón indescriptible" ( $A P: 60)$, lugar siniestro, cuya planta tiene la forma de la swástica. Es un edificio de múltiples pasillos, torres y espacios donde suceden hechos inauditos en el transcurso de la narración, entre ellos las desapariciones que son explícitamente relacionadas con la política represiva del Protector y justificadas en los

16 La actitud frente a la amenaza fascista-nazi que muestra esta película comparte parcialmente la de la novela de Lihn, aunque ésta tal vez manifieste un cinismo más locuaz y determinante. 
discursos del propio dictador y de sus funcionarios. Con estos sucesos a nivel narrativo, la novela denuncia la dictadura o cualquier régimen autoritario y la incapacidad de intervenir desde otro lugar de enunciación.

El espacio distópico de la isla, además del extraño hotel Cosmos, es otro elemento clave de la configuración espacial de la novela. Miranda tiene la ya mencionada afinidad surrealista con el nombre y la existencia apócrifa del país en la película de Buñuel, pero Pedro Lastra rastrea también las filiaciones del espacio imaginario de esta república desde el Nostromo (1904) de Conrad, pasando por el Tirano Banderas (1926) de Valle-Inclán hasta llegar a El señor presidente (1946) de Asturias y El recurso del método (1974) de Carpentier (Lastra 1990: 114-115). Lihn, a su vez, señala que para la creación de la novela tuvo en cuenta la Oceanía de Orwell en 1984 (1949), porque es un "espacio en el que se condensan países distintos y sistemas opuestos, lo que Alfred Jarry proponía como el principio patafísico de 'la unión de los contrarios"'. Como en la Oceanía, también en la utopía negativa de Miranda el "triunfo constante del discurso vacío, de la cháchara torrencial, ha clausurado toda otra forma de hacer uso de la palabra" (Lihn citado en Lastra 1990: 115). La diferencia, sin embargo, reside, según Lihn, en que en 1984 se mantiene la distinción entre palabra vacía y palabra de verdad, mientras en El Arte de la Palabra todo es vacío e irrisión. No obstante, como señala Lange en su ensayo sobre la paranoia de la modernidad tardía en Lihn, el simulacro de la República también apunta a la marginalidad fracasada de Latinoamérica, una marginalidad exhibida en los discursos sobre la modernización política-económica y la modernidad literaria que producen una "doble contradicción: no solo el proyecto político de los estados nacionales resulta de una adquisición fallida de un proyecto fallido, el sueño de la razón, sino que su crítica 'literaria' se funda en la adquisición de un ideal de belleza apropiado a la velocidad de un rayo" (Lange 2007: s.p.).

En el contexto de la colonización territorial, política y mental, la rivalidad y la guerra entre Miranda y Guanahaní es otro elemento del discurso burlesco. Ese nombre indígena de la primera isla de Las Indias que pisó Colón en 1492, y que hasta hoy día no ha sido identificada geográficamente, en la novela es la tierra firme en el otro lado del río/mar Amauroto -a su vez nombre de ciudad en la Utopía de Tho- 
mas Morus- que aquí separa Miranda del resto del mundo. Por otro lado, no es de extrañar que Miranda mantenga una relación explícitamente amistosa con el Tercer Reich. Su consejero cultural, el nazi Kurt Kersten, es asesinado, no obstante, durante el partido de fútbol entre Miranda y Guanahaní, donde se desempeña como árbitro.

Vinculando lo desarrollado hasta aquí con la forma en la que $E l$ Arte de la Palabra presenta una estrategia de memoria cultural, es interesante recurrir a lo que el propio Lihn dice sobre su novela como

modelo de memorial, aunque de papeles heterogéneos, un 'file', como se diría en Estados Unidos: archivo, registro, carpeta, archivador, protocolo, [...] papeles que quedan como saldo de un cierto congreso cultural celebrado virtualmente, o como su propia frustración, en Miranda, y que se archivan en vez de ser arrojados al canasto o entregados al viento que los disperse (Lastra 1990: 116).

Se trata pues de una memoria de palabras sueltas que exhibe el propio proceso de formación de esa memoria en la escritura; una escritura, por ende, que se desplaza constantemente, atravesando un campo de palabras vacías, desviadas en sus atribuciones y significaciones corrompidas en los regímenes autoritarios y totalitarios que a su vez reclaman contradictoriamente basarse en la historia moderna de la humanidad. Esta memoria opera ciertamente como antimemoria que, en su gesto deconstructivo, alude a otro espacio, al propio mecanismo mnémico que en su forma desaforada, enloquecida y esquizofrénica podría señalar otros lugares de la memoria, heterotopías del propio mecanismo entre olvido y recuerdo.

\section{El Paseo Ahumada}

Un lugar distinto de memoria y de resistencia en la escritura de Lihn es el poemario El Paseo Ahumada de 1983. Se publicó en Santiago de Chile, en plena dictadura, en formato de cuadernillo, sin paginación y con una foto en la tapa que muestra una escena del paseo peatonal mencionado en el título. Está impreso en papel de diario e imita una publicación periódica; en el interior se encuentran poemas, dibujos y fotos en blanco y negro, y varios títulos imitan y parodian los titulares de los medios masivos: "Noticias de un astronauta del futuro candidato a la presidencia del mundo", "Sacerdote satánico no absuelve a cualquiera", "Se apareció Cristo en el Paseo Ahumada está bueno de jodé", "Ciegos instrumentales tocan eeme contratados en el Ahumada. 


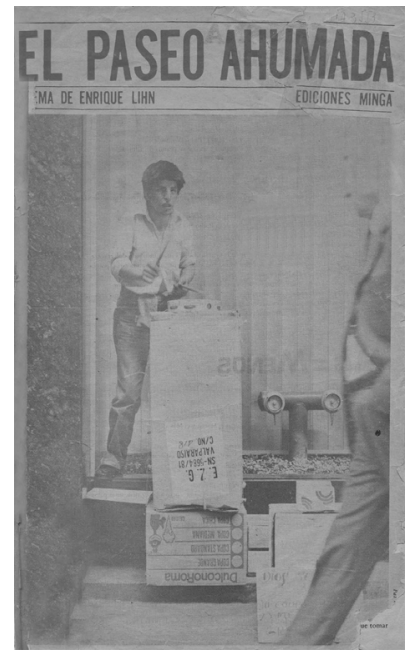

Lo que puede el Japón", "Nacionales: el desmemorizador: un aparato de primera necesidad", "Nada nuevo en el encuentro de Cachagua entre el de Humboldt y los magallánicos", "Abdica reina de los mendigos -no sabía que eran tantos- declara". El propio Lihn, hasta que fuera detenido por las autoridades, hizo público los textos con un megáfono mediante una intervención callejera en el mismo Paseo Ahumada, la calle principal en el centro de Santiago y, en tiempos de dictadura, habitado por mendigos que forman parte integral de este "símbolo del programa económico de la Dictadura Militar", como señala Francisca Lange (2006b) en sus notas sobre este cuadernillo de poemas. El Paseo Ahumada es, entonces, un acto y un texto de resistencia y de memoria en muchos sentidos, y la mendicidad funciona como

eje temático y metafórico del texto: la mendicidad que produce el modelo, la mendicidad mental de quien lo impone y también la mendicidad con que muchos han buscado leerlo (mendicidad entendida en su sentido textual, como el que pide, pero también como la actitud humillante del que se somete a dicho acto) (Lange 2006b: s.p.).

Por un lado, el libro es una contribución original a la poesía urbana y callejera. Recuerda y cita desde su formato de collage el proyecto de Quebrantahuesos, el diario mural instalado en la misma zona hacía 30 años, y en un sentido más internacional, cita varios artefactos y happenings del pop art de los años 60 y 70, al incorporar distintas tipografías, el juego irónico de un escrito a mano en la contratapa que es igualmente reproducido en serie, la integración de dibujos hechos por Germán Arestizábal, un habitante sobre ruedas del Paseo, y fotos de Paz Errázuriz y Marcelo Montecino, "gente del Paseo Ahumada". Es un proyecto que reúne varios actores de la calle y se inscribe de esta manera como trabajo colectivo de prácticas de escritura y de memoria en la topografía urbana que de esta manera presenta un contramundo, el "Gran Teatro de la crueldad nacional y popular, donde se practican todos los oficios de la superviviencia" (Lihn 1983). El epílogo de la contratapa reivindica una nueva apropiación del espacio urbano, a 
través de una poesía radicalmente cruel en el sentido de Artaud. La otra razón para publicar en el formato de cuadernillo es más bien una necesidad: las publicaciones periódicas, al contrario de los libros, no pasaban por la censura, y a Lihn le interesaba llegar al mayor número posible de personas en la vía pública.

Pasando al nivel textual, son llamativas las estrategias discursivas que aplica Lihn frente a una censura abrumadora. Hay títulos con referencias explícitas a la situación del país y a la violencia ejercida por el régimen, por ejemplo "Cámara de tortura", "¿Qué pecado tiene el pueblo para que lo castiguen tanto?", o "Strip Tease de la recesión". Los poemas operan con discursos heterogéneos provenientes del habla popular, de citas bíblicas, del hermetismo poético, del estilo directo y dialógico; y utilizan como recursos fundamentales la parodia y la ironía. La dislocación y la dispersión de los versos libres y en su mayoría desarticulados son otras características centrales del discurso poético de Lihn. Como "vertiente poética" de la teoría de la cháchara y la palabra vacía en El Arte de la Palabra, Lange inscribe el poemario en la conceptualización de la poesía situada, propuesta por el mismo autor en una de sus entrevistas:

Yo quisiera rescatar un concepto de la literatura que no excluye los datos de la experiencia. No se trata de la presunción realista de una literatura que sería el reflejo artístico de la realidad objetiva [...]. Lo que yo he intentado hacer al menos, por mucho que parezca irrealista, es el producto de un cierto enfrentamiento con la situación (Luis Diez citado en Lange 2006b: s.p.).

Para demostrar las estrategias de memoria y de escritura situacionista en este poemario, quisiera entrar en la lectura del primer poema, "Su limosna es mi sueldo Dios se lo pague", que funciona como un programa que se despliega en varios poemas reunidos aquí. Desde el título está instalada la referencia a la mendicidad, tema central en muchos de los poemas y representada por El Pingüino, personaje-habitante del escenario del Paseo. Lo vemos en la tapa del cuadernillo, donde también encontramos parte del título del poema, escrito a mano sobre el cartoncito delante del Pingüino en acción y medio tapado por un señor vestido de traje y representante del capital chileno que apoya a la dictadura. El Pingüino se convierte desde varios niveles de comunicación en figura-símbolo del Paseo, pero también en contrafigura irónica del hablante-poeta, quien se dirige a él en varios poemas. Aquí va el texto: 
Su limosna es mi sueldo Dios se lo pague

Un millón y medio de subempleados mendigos suscribirían el lema

si los dejaran chillar como a éste y a otros tantos pocos en el Paseo Ahumada

Se autoapoda El Pingüino y toca un tambor de cualquier cosa con su pezuña de palmípedo

Qué dislocado sentido del humor

Toca que toca sin son ni ton zapateo

de un epiléptico en tres de espectacularse

el graznido de un palo

Privilegiados él y otros mendigos de verdad a quienes les está permitido ir derecho al grano de limosna

como en su caso, a veces, sin ningún mérito artístico

Privilegiado el ciego que toca su flauta dulce a la vaciada luz de esta luna

Privilegiado el sordo del acordeón, artista exclusivo de la Radio-Noche

y el mudo que lisa y llanamente canta

-el que quiere celeste que le cueste-

En Huérfanos entre Ahumada y Estado las papas de la mendicidad se están quemando dulcemente

Privilegiada la Volada, que estropajosa de niños forma con ellos un túmulo prefunerario porque de ella es el reino de la Mendicidad

Privilegiados todos ellos porque de estos corderos está hecho el rebaño de los casos omisos

¿eh, Pingüino? A ti nadie te toca un pelo

Caso omiso hacen de ustedes esos robots que se mueven armados hasta los dientes

Con sus lobos de mano y sus metralletas eléctricas (Lihn 1983: s.p.).

El hiperbólico número del primer verso indica la pobreza reinante en Chile en esos momentos, provocada por el capitalismo salvaje adoptado por el régimen pinochetista y enfatizada aquí por el oxímoron irónico de "mendigos subempleados". El segundo verso ya insinúa una práctica de censura, porque no todos pueden hablar y pedir limosna. El que sí puede hacerlo es El Pingüino que aparece en el tercer verso, un ser excéntrico, dislocado, epiléptico, "privilegiado" por su situación desesperada, fuera de la ley, y "sin ningún mérito artístico". Luego se enumeran otros privilegiados del Paseo Ahumada que pueden pedir limosna: el ciego, el sordo, el mudo, la Volada, todos habitantes del "reino de la Mendicidad", enunciado que se desplaza constantemente al centro del poema y del libro. Después viene una explicación aludiendo al texto bíblico: son corderos inofensivos del rebaño de los "casos omisos", pobres criaturas sin voluntad propia que no les interesan a los "robots armados hasta los dientes/Con sus lobos de mano y sus metralletas eléctricas". Antes de terminar el poema con estos ver- 
sos, el poeta se dirige al mendigo: " $\mathrm{eh}$, Pingüino? A ti nadie te toca un pelo". En esta verbalización de una envidia absurda se expresa de manera más clara la estrategia de la confrontación paradójica en la relación poeta-mendigo. En el epílogo de la contratapa del cuadernillo se prolonga esta equiparación irónica:

el autor de estas páginas escritas con smog agradece al Decenio (de la dictadura) la oportunidad que le ha dado de escribir con las manos amarradas; proeza que quiere agregar a las que realizan, día a día, los subempleados y mendigos del Paseo, sus semejantes, sus hermanos (Lihn 1983: s.p.).

El poeta-mendigo -en su irónica confraternización baudelairianaabre un contraespacio de memoria individual, colectiva y poética que, al igual que la estética de la cháchara de don Gerardo de Pompier en El Arte de la Palabra, es una antimemoria que en este caso pone en escena una estrategia intermedial entre la palabra, el dibujo, el manuscrito, la imagen fotográfica, y la acción callejera para desenmascarar y contrariar los espacios del discurso oficial del régimen. El cuadernillo denuncia la grotesca simbiosis de los poderes político-económicos desplegada en el más significativo y emblemático espacio público y social de memoria urbana en el centro de Santiago.

Los dos libros analizados representan dos polos de una escritura autoreflexiva y (auto)deconstructiva: mientras El Arte de la Palabra expone y satiriza el lenguaje en su propia configuración fascista y siniestra, y mientras desmonta el discurso político y poético como artificio del poder en la construcción de una República Miranda distópica, ofrece un espacio de palabras desplazadas y autocríticas que abren una textura literaria e intermedial de antimemoria. El Paseo Ahumada se dedica a la resistencia puntual, concreto y visible frente al "aniversario" de una situación insostenible en Chile, con todos los medios disponibles, y con un carácter conmemorativo, transgresor. ${ }^{17}$ El proyecto de escritura pre/post/anti/dictatorial de Lihn reúne incó-

17 En el contexto de la memoria literaria como memoria cultural es interesante el proyecto de reedición de poesía de los años 70 y 80, llevado a cabo por Ediciones Diego Portales. El nuevo Paseo Ahumada de 2003 es otro que el original de 1983, con una tapa que muestra una foto del poeta, con los textos ordenados y coherentes sobre un papel blanco y caro, sin dibujos y con fotos, de las que solo unas pocas son originales. La colección responde al deseo de rescate de un patrimonio literario importante, y a la vez anula la actitud y la estética inconclusas de la primera edición que tuvo un tiraje muy breve. Cf. Lange 2006b. 
modamente política y memoria, literatura e historia, y no deja margen para los cantos generales de todas las épocas:

No hacemos nada, no decimos nada

¿Con qué ropa subir ahora el Macchu Picchu

Y abarcar, con tan buena acústica, el pastel entero de la historia

Siendo que ella se nos está quemando en las manos?

("Canto general", en Lihn 1983: s.p.) ${ }^{18}$

\section{Bibliografía}

Arendt, Hannah ([1953] 2006): Los origenes del totalitarismo. Madrid: Alianza.

Avelar, Idelber (1999): The Untimely Present. Postdictatorial Latin American Fiction and the Task of Mourning. Durham/London: Duke University Press.

Barthes, Roland (2003): El placer del texto y Lección inaugural. Buenos Aires: Siglo XXI.

Benjamin, Walter (2008): Tesis sobre la historia y otros fragmentos. México, D.F.: Itaca.

Brunner, José Joaquín (1983): “La cultura política del autoritarismo”. En: Chile 1973198? Santiago: Flacso, pp. 211-228. (<www.cronopio.flacso.cl/fondo/pub/ publicos/1983/libro/000035.pdf>.

- (2002): Globalización cultural y posmodernidad. Santiago de Chile: Fondo de Cultura Económica.

Cánovas, Rodrigo (1986a): Texto y censura: las novelas de Enrique Lihn. Santiago: CENECA.

- (1986b): Lihn, Zurita, Ictus, Radrigán: literatura chilena y experiencia autoritaria. Santiago: Ainavillo.

Foxley, Carmen (1995): Enrique Lihn: escritura excéntrica y modernidad. Santiago: Universitaria.

Haverkamp, Anselm/Lachmann, Renate (eds.) (1991): Gedächtniskunst, Raum - Bild - Schrift. Frankfurt am Main: Suhrkamp.

Huyssen, Andreas (2002): "Pretéritos presentes: medios, política, amnesia". En: Huyssen, Andreas: En busca del futuro perdido. Cultura y memoria en tiempos de globalización. Buenos Aires: Fondo de Cultura económica, pp. 13-40.

Lange, Francisca (2006a): Teoría estética y crítica en dos textos de Enrique Lihn: Lihn \& Pompier $y$ El Paseo Ahumada. Tesis. Santiago de Chile: Universidad de Chile, Facultad de Filosofia y Humanidades.

- (2006b): “Algunas notas sobre El Paseo Ahumada de Enrique Lihn". En: $<$ www.letras.s5.com/el221006.htm> (30.05.2009).

18 Neruda es el anti-poeta para Lihn en muchos sentidos, en este poema explícitamente. 
- (2007): Sobre "El arte de la palabra" y la paranoia de una modernidad tardía. inédito.

Lastra, Pedro (1990): Conversaciones con Enrique Lihn. Santiago de Chile: Atelier.

Lihn, Enrique (1978): Lihn \& Pompier. Santiago de Chile: Ediciones del Departamento de Estudios humanísticos.

- (1980): El Arte de la Palabra. Barcelona: Pomaire.

- (1983): El Paseo Ahumada. Santiago de Chile: Miga.

- (1997a): El circo en llamas. Ed. de Germán Marín. Santiago: Lom.

- (1997b): "El caso Padilla". En: Lihn, Enrique: El circo en llamas. Ed. de Germán Marín. Santiago de Chile: Lom, pp. 432-435.

- (1997c): "Gerardo de Pompier". En: Lihn, Enrique: El circo en llamas. Ed. de Germán Marín. Santiago de Chile: Lom, pp. 541-600.

- (1997d): "Literatura y dictadura". En: Lihn, Enrique: El circo en llamas. Ed. de Germán Marín. Santiago de Chile: Lom, p. 495.

- (1997e): "Política y cultura en una etapa de transición al socialismo". En: Lihn, Enrique: El circo en llamas. Ed. de Germán Marín. Santiago de Chile: Lom, p. 465.

Richard, Nelly (1986): Margins and institutions. Art in Chile since 1973. Melbourne: Art \& Text.

- (ed.) (2004): Utopía(s) 1973-2003. Revisar el pasado, criticar el presente, imaginar el futuro. Santiago de Chile: Universidad Arcis.

Sánchez, Yvette/Spiller, Roland (eds.) (2008): La poética del fracaso. Tübingen: Narr.

Spiller, Roland/Heydenreich, Titus/Hoefler, Walter/Vergara Alarcón, Sergio (eds.) (2004): Memoria, duelo y narración. Chile después de Pinochet: literatura, cine, sociedad. Madrid/Frankfurt am Main: Iberoamericana/Vervuert.

Todorov, Tzvetan (2000): Los abusos de la memoria. Buenos Aires: Paidós. 